\title{
Antemortem measurements of neurotransmission: possible implications for pharmacotherapy of Alzheimer's disease and depression
}

\author{
P T Francis, M N Pangalos, P H Stephens, J R Bartlett, P K Bridges, A L Malizia, \\ D Neary, A W Procter, D J Thomas, D M Bowen.
}

\begin{abstract}
Aspartic acid, 5-hydroxyindoleacetic acid, glutamic acid, homovanillic acid and 3-methoxy-4-hydroxyphenylethylene glycol was determined in samples of ventricular fluid from 82 subjects. Laminar distribution of the total number $\left(B_{\max }\right.$ value) of serotonin $1 A$ receptors was determined on seven neurosurgical samples of neocortex. Apart from an association in a small subgroup of subjects between homovanillate concentration and corticosteroid medication, no complicating influences of treatment preceding operation were found. The content of the serotonin metabolite alone was significantly reduced in intractable depressive illness (bipolar and major depressive disorders) compared with neurological conditions subdivided into Alzheimer's disease, other dementias and other conditions. There was no other significant difference between these groups for the compounds measured. The total number of serotonin $1 \mathrm{~A}$ receptors was highest in the superficial layers, being considerably higher than in the rat, irrespective of cortical layer. This part of the study indicated that these receptors are important for regulating activity of human corticocortical glutamatergic neurons. The results are discussed in relation to treating depression with serotonergic agents and targeting corticocortical glutamatergic neurons as well as acetylcholine in Alzheimer's disease.
\end{abstract}

(F Neurol Neurosurg Psychiatry 1993;56:80-84)

Development of pharmacotherapy for Alzheimer's disease with agents that would aim to improve, if not restore, neurotransmission has been viewed with pessimism. ${ }^{1-3}$ The disease is a slowly progressing disorder, yet such conclusions were based on biochemical analyses of postmortem tissue, often from selected severely affected subjects at the end-point of the disease process, that indicated multiple transmitter deficits had occurred. Similarly, it could be concluded that complex transmitter related changes were also a feature of depressive illness as a myriad of antidepressant drugs, with a host of proposed transmitter actions, have recently emerged. ${ }^{4} \mathrm{~A}$ few studies have provided information about neurotransmission in living patients at a more central level than may be obtained by studying lumbar cere- brospinal fluid. For instance, the investigation of ventricular fluid showed reduced homovanillate concentration in patients with Parkinson's disease. ${ }^{5}$ Analysis of cortical tissue removed at neurosurgical craniotomy is another approach and has included the study of transmitter receptors. ${ }^{67}$ Results reported here extend these approaches to provide new information about catecholamine, excitatory dicarboxylic amino acid and serotonin transmission of human brain, in particular with respect to Alzheimer's disease and depressive illness.

\section{Methods}

Samples of ventricular cerebrospinal fluid were obtained from 52 patients who had intractable depression. Electroconvulsive therapy (ECT), as well as high dose and combination drug treatment had not been effective during the period of presurgical assessment and so they underwent the psychosurgical operation of stereotactic subcaudate tractotomy. ${ }^{8}$ All patients had fulfilled the requirements of the Mental Health Act, 1983. Details of current and previous treatments were recorded. Drugs were classified into antidepressants, antipsychotics, tranquillisers, lithium salts, and other psychotropic drugs; patients suffered with affective disorders and were diagnosed according to the research diagnostic criteria. ${ }^{910}$ Forty six patients had either major depressive disorder or bipolar disorder and six had other psychiatric disorders (four with obsessive compulsive disorder and two with phobic disorder). Patients with major depressive disorder were subclassified as unipolar psychotic or unipolar simple according to presence or absence, respectively, of delusions or hallucinations, or both. ${ }^{9}$ The unipolar psychotic group had three men and five women with a mean age of $60(46-74)$ years. The unipolar simple group had twelve men and ten women with a mean age of $48(21-68)$ years. The bipolar disorder group had two men and fourteen women with a mean age of 47 (29-68) years.

The second group, with obsessive compulsive and phobic disorders, had four men and two women with a mean age of $42(27-55)$ years. During the course of the operation, air encephalography was performed to identify the precise location of the lesion and cerebrospinal fluid was removed from the lateral ventricle of necessity. Samples of CSF were maintained at minus $70^{\circ} \mathrm{C}$ until the contents of free amino acids (aspartic acid and glutamic acid) 
and monoamine transmitter metabolites (5-hydroxyindoleacetic acid, 5-HIAA; homovanillic acid and 3-methoxy-4-hydroxyphenylethylene glycol, MHPG) were determined (blind to patient characteristics) by high performance liquid chromatography and fluorescence detection following derivatisation with an $o$-phthaldialdehyde reagent for amino acids $^{11}$ and electrochemical detection for monoamines. ${ }^{12}$ An anomalous glutamate value $(10.8 \mathrm{nmol} / \mathrm{ml})$ was excluded from the analysis.

Cerebrospinal fluid was also obtained from the lateral ventricles of adult neurological patients including samples from procedures for insertion of ventriculoperitoneal shunts and craniotomy for brain tumours. This group had six men and six women with a mean age of 48 (21-69) years. Diagnoses were normal pressure hydrocephalus (three), aqueduct stenosis (three), craniopharyngioma (two), posterior communicating artery aneurysm, malignant glioma, meningioma and epidermoid tumour (one each). Shunts were not inserted into the patient with meningioma and one patient with craniopharyngioma. In those shunted, two patients were using carbamazepine, one in combination with diazepam and the other with corticosteroids. In the craniotomy subgroup, there were two patients using antiepileptics and corticosteroids. The other neurological samples of ventricular fluid were obtained from demented patients at diagnostic craniotomy of the superior frontal lobe. ${ }^{13} \mathrm{~A}$ group with Alzheimer's disease histology had six men and three women with a mean age of 60 (54-66) years. The remainder had no specific histological changes, five men and two women with a mean age of 54 (50-66) years. The demented patients were not receiving any drugs during at least the week preceding operation. There were no significant differences in age between the groups except for the patients with Alzheimer's disease, who were older $(p<0.05)$ than the other groups.

The investigated compounds were detectable in all samples assayed except for glutamate in 10 subjects, where there were contaminating peaks.

During the psychosurgical operation, a small piece of cerebral cortex was always removed bilaterally from the frontal lobes, to make insertion of a cannula as safe as possible. Cryostat sections were prepared from two antidepressant free ${ }^{10}$ and two antidepressant treated $^{10}$ patients with major depressive and bipolar disorders, three age-matched controls (whose frontal cortex appeared normal when removed at neurosurgery for access to deep tumours) and rats of the Sprague-Dawley strain. Sections were incubated with eight concentrations $(0.5-5 \mathrm{Tnmol} / \mathrm{l})$ of $\left[{ }^{3} \mathrm{H}\right]-8$-hydroxy-2(n-dipropylamino)tetralin, the prototypical serotonin 1A partial agonist, with quantitation using computerised receptor autoradiography (Quantimet 570, Leica, Cambridge). ${ }^{14,15}$

Results were expressed as mean (SE). Variances of group means were compared using Fisher's test of exact probability and, if there was no significant difference, one way analysis of variance (ANOVA). The least significant difference test, if appropriate, or the two-tailed Student's $t$ test were used to compare group means. Where there was a significant difference, Kruskall-Wallis, ANOVA, if appropriate, and the Mann-Whitney U-test or Wilcoxon 2 sample test were used to compare group means.

\section{Results}

Measured compound concentrations in the neurological patients were not influenced by drug treatment, operation type, age, sex or response to operation (data not shown) except for homovanillate which was higher $(p<0.01)$ in corticosteroid-treated subjects. For the patients with affective disorders, measured compound concentrations were not influenced by age or sex, except for homovanillate content with age (Pearson's correlation $r=-0 \cdot 40, \mathrm{n}=$ $38, \mathrm{p}<0.02)$. Measured compound concentrations were not affected by drug treatment (antipsychotics or antidepressants, including lithium) or ECT, based on treatment during the six months (or 12 months for ECT) preceding collection of sample (data not shown). Most patients studied (31) were receiving drugs from two categories or less. There were no differences in the concentrations of investigated compounds between this group and the group of 21 subjects receiving polypharmacy, that is, drugs from three or more categories (data not shown). For those without polypharmacy there was no effect of drug treatment or ECT on the monoamine metabolites or amino acids (data not shown).

The figure shows that the major serotonin metabolite (5-HIAA), aspartate and glutamate values were distributed over relatively wide ranges, except for aspartate in the neurological subjects. When these values for the various groups were compared, no significant differences were found in aspartate and glutamate concentrations. This was also the case for metabolites of catecholamine transmitters (homovanillate and MHPG: table 1). Whereas the 5-HIAA value was significantly lower in the depressed group (DEP, fig), compared with neurological groups, the concentration of 5-HIAA and those of the other investigated compounds did not significantly differ between subgroups (data not shown).

5-HIAA content was not significantly correlated with aspartate or glutamate values for any group of comparable numbers (data not shown), except for the demented subjects where aspartate and 5-HIAA concentrations were negatively correlated (Pearson's correlation $r=-0.63, \mathrm{n}=15, \mathrm{p}=0.01$ ).

Within the human neocortex there were more serotonin $1 \mathrm{~A}$ receptors in superficial layers than in either deep or superficial layers of the rat (table 2). In the human, binding was highest in superficial layers and by comparison with adjacent histological sections (not shown) it was established that this region of the autoradiograph corresponded mainly to cortical layers $\mathrm{I}$ and II. $^{16}$ Binding parameters 

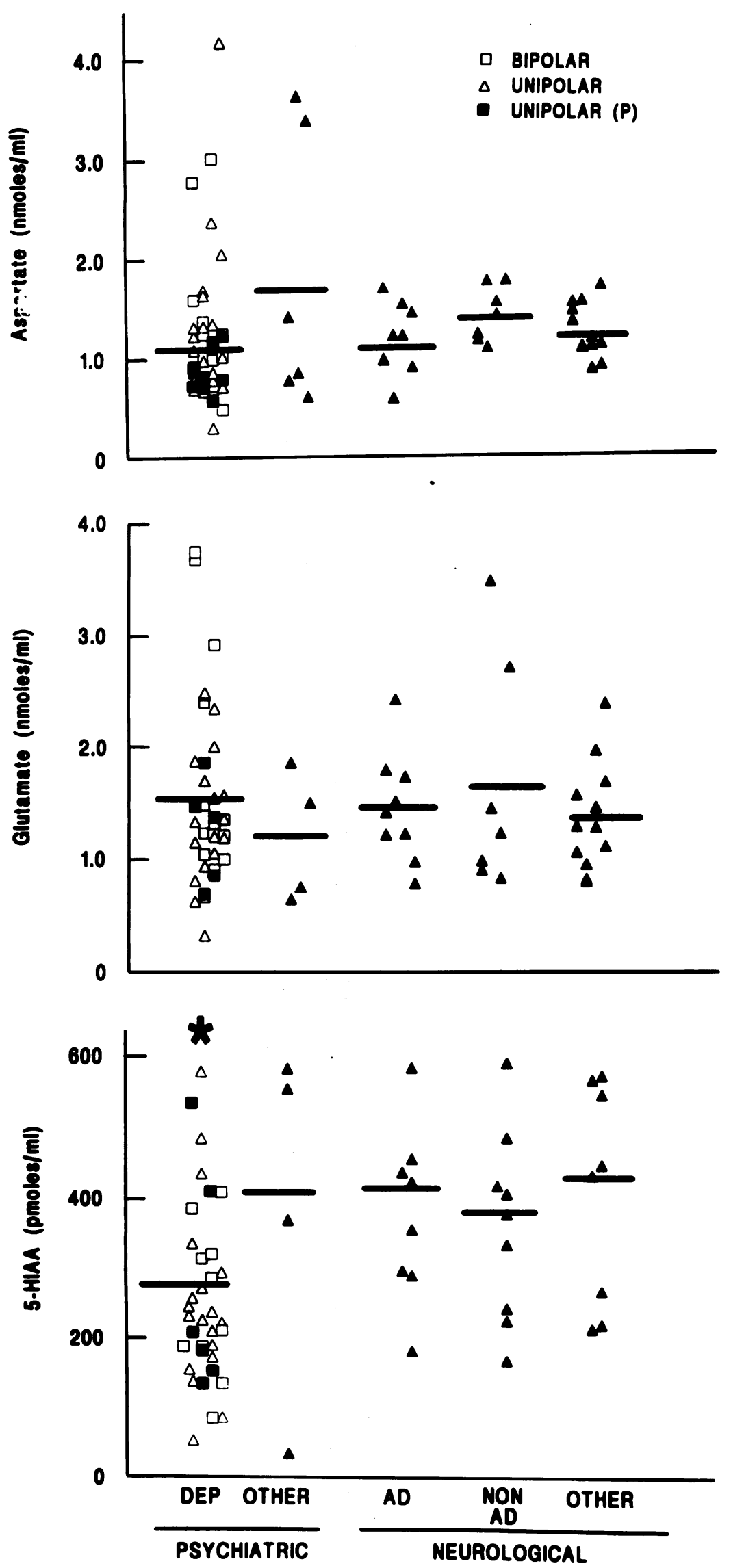

Figure 1 Excitatory dicarboxylic amino acids and the major serotonin metabolite 5-HLAA in ventricular fluid. Concentrations for individual patients and means (horizontal lines) are shown for five groups of patients: DEP (bipolar or major depressive disorders, subclassified as discussed in the text); Other (other psychiatric disorders); $A D$ (Alzheimer's disease); Non-AD (no specific histological changes); and Other (other neurological patients). The asterisk identifies the only significant difference $(p<0.05)$ between groups (ANOVA and the least significant difference test; groups consisting of only four patients were excluded from the analysis). appeared independent of medication (data not shown; see also ${ }^{17}$ ) and were lower in the DEP samples compared with controls, in superficial layers only (table 2).

\section{Discussion}

Laminar distribution of binding to the serotonin $1 \mathrm{~A}$ receptor was different in postmortem human tissue compared with rapidly processed rat brain, ${ }^{18-20}$ so it was important to eliminate the possibility that the difference was a postmortem artefact. To our knowledge this is the first study to employ rapidly processed human tissue and is also new, for both humans and a laboratory animal, in the use of a selective $\left[{ }^{3} \mathrm{H}\right]$ ligand to determine kinetic parameters for the receptor in superficial and deep cortical layers. In the rat the receptor was enriched (by comparison with all other receptors studied, ${ }^{1521}$ ) on corticofugal pyramidal neurons, ${ }^{14}$ is which almost certainly released either aspartate or glutamate as transmitter. ${ }^{22}$ Human neocortical pyramidal neurons studied electrophysiologically using intracellular recordings, ${ }^{6}$ responded to the prototypical serotonin 1A partial agonist used here. In Alzheimer's disease, the overall $B_{\max }$ value for the receptor was reduced in the neocortex, where pyramidal neuronal loss had occurred. ${ }^{23}$ A role for these cells in depression has been proposed $^{924}$ and this was consistent with the low $B_{\max }$ value in table 2 for depression. In human brain the $B_{\max }$ value was highest in superficial layers (table 2), corresponding to cortical layers I and II (see above). These observations provide evidence that, in humans, the receptor is predominantly a component of ipsilateral projecting ${ }^{25}$ corticocortical pyramidal neurons. For deep and superficial cortical layers of the rat brain, the $B_{\max }$ value was lower than for human superficial layers (table 2), yet it is well known that neuronal density is higher in the rat. This suggests that humans have more serotonin $1 \mathrm{~A}$ receptors per corticocortical neuron and that the receptors are important for regulating activity of the cells, which probably release glutamate. ${ }^{26}$ Thus it should be possible to discover drugs to target this subpopulation of cortical neurons.

Apart from the biochemical analyses, histological investigation of Alzheimer's disease has also focused on the end-point stage, and it has been emphasised that interconnections between many parts of the cortex are disrupted at multiple levels. ${ }^{3}$ Even if new lines of research (as reviewed ${ }^{27}$ ) eventually yield treatment to slow progression of pathology, drugs that affect neurotransmission will still be needed in most patients to improve functional activities that are already impaired. The present data indicate relative sparing of dopamine, noradrenaline and serotonin (table 1, fig), as has already been found for somatostatin. ${ }^{13}$ This is consistent with most results for the transmitter biochemistry of cortical biopsy samples, and includes $\gamma$ - aminobutyric acid (as reviewed ${ }^{26}$ ). Although the present results do not indicate any abnormality of ventricular 5-HIAA concentration, 5-HIAA and aspartate content may 
Table 1 Concentrations of catecholamine metabolites, mean (SE), in ventricular fluid

\begin{tabular}{llll}
\hline Patient groups & No of patients & $\begin{array}{l}\text { Homovanillate } \\
(\text { pmol/ml) }\end{array}$ & $\begin{array}{l}\text { MHPG } \\
(p m o l / m l)\end{array}$ \\
\hline Psychiatric & $34-35$ & $1444(106)$ & $45 \cdot 1(4 \cdot 5)$ \\
DEP & 4 & $2436(583)$ & $50 \cdot 1(8 \cdot 8)$ \\
Other & $7-8$ & $1190(159)$ & $32 \cdot 4(4 \cdot 9)$ \\
Neurological & 9 & $1008(122)$ & ND \\
AD & $5-8$ & $985(49)$ & $29 \cdot 7(4 \cdot 7)$ \\
Non-AD & Other & &
\end{tabular}

$\mathrm{ND}$, not determined; $\mathrm{DEP}=$ bipolar or major depressive disorders; $\mathrm{AD}=$ Alzheimer's disease Patient groups as defined in the text, except that homovanillate values of corticosteroid-treated patients with ventriculoperitoneal shunts and brain tumours were excluded. There were no significant differences (ANOVA, least significance difference test; groups comprising only four patients were excluded from the analysis).

Table 2 Binding parameters of the serotonin $1 A$ receptor, mean (SE), in frontal neocortex of human (region of Brodmann area 9) and rat (Fr1/FR2) brain

\begin{tabular}{|c|c|c|c|}
\hline \multirow[b]{2}{*}{ Cortical layer } & \multicolumn{2}{|l|}{ Human * } & \multirow[b]{2}{*}{$\begin{array}{l}\text { Rat } \\
(n=5)\end{array}$} \\
\hline & $\begin{array}{l}D E P \\
(n=4)\end{array}$ & $\begin{array}{l}\text { Control } \\
(n=3)\end{array}$ & \\
\hline $\begin{array}{l}\text { Superficial } \\
\mathbf{B}_{\max }(\mathrm{fmol} / \mathrm{mg} \text { tissue }) \\
\mathbf{K}_{\mathrm{d}}(\mathrm{nmol} / \mathrm{l}) \\
\text { Deep }\end{array}$ & $\begin{array}{l}62.3(2.9) \dagger \\
0.50(0.09)_{+}^{+}\end{array}$ & $\begin{array}{c}87.5(4 \cdot 5) \\
0.83(0.09)\end{array}$ & $\begin{array}{l}28 \cdot 3(1 \cdot 8) \\
2 \cdot 54(0 \cdot 38)\end{array}$ \\
\hline $\begin{array}{l}\mathbf{B}_{\max }(\mathrm{fmol} / \mathrm{mg} \text { tissue }) \\
\mathrm{K}_{\mathrm{d}}(\mathrm{nmol} / \mathrm{l})\end{array}$ & $\begin{array}{c}25 \cdot 3(1 \cdot 3) \\
0.93(0 \cdot 25)\end{array}$ & $\begin{array}{l}28 \cdot 3(5 \cdot 8) \\
1.03(0 \cdot 32)\end{array}$ & $\begin{array}{l}36.8(3.4) \\
1.75(0.48)\end{array}$ \\
\hline
\end{tabular}

DEP = bipolar or major depressive disorders.

$\star$ Mean $B_{\text {max }}$ value for superficial layers of all samples $(n=7)$ was higher $(p<0.005$, Student's $t$ test) than for either deep or superficial layers of the rat.

$+\mathrm{p}<0.01$.

$\ddagger \mathrm{p}<0.06$, from control (Student's $t$ test), deep layers showed no significant differences from control.

be abnormally related in demented patients. Even in the postmortem Alzheimer's diseased brain, however, half the many cortical areas assayed had no evidence of a selective reduction in presynaptic serotonergic activity. Indeed the surviving serotonergic nerve endings seem most active in the most demented patients (for reference $\operatorname{see}^{28}$ ).

The lack of change in excitatory amino acids (fig) suggests that corticostriatal excitatory neurons (as reviewed ${ }^{22}$ ) are not affected appreciably. This provides further evidence that Alzheimer's disease is characterised by two selective and critical deficits: circumscribed corticocortical glutamatergic ${ }^{29}$ and cholinergic degeneration. Cortical pyramidal neurons are probably subject to cholinergic modulation $^{62130}$ so improved cholinomimetics ${ }^{31}$ should complement approaches aimed at slowing the progression of the pathology. Partial agonists of glutamate may also be useful. ${ }^{2932}$ Selective serotonin 1A receptor antagonists $^{334}$ should promote all effects of the remaining glutamate transmitter pool by inhibiting the tonic hyperpolarising action of endogenous serotonin on pyramidal neurons, thereby compensating for reduced glutamatergic transmission. It is well known that drugs showing serotonin 1A agonism reduce aggression and depression in animals so this strategy will require careful evaluation. Use of rats may be inadequate to predict clinical consequences of treatment with $1 \mathrm{~A}$ drugs because the receptor in this species and humans clearly have different distributions (table 2).

Aspartate has been proposed as the major transmitter of the corticostriatal excitatory neurons. ${ }^{22}$ The lack of change in the concen- tration of this amino acid in ventricular fluid from depressed patients indicates that these neurons are preserved. This is supported by the observation that the serotonin $1 \mathrm{~A}$ receptor was also unchanged in the deep cortical layer (table 2). In cerebral cortex from a similar group of patients, aspartate concentration was increased, ${ }^{9}$ so the most straightforward interpretation for reduced $1 \mathrm{~A}$ receptor numbers (table 2) and increased aspartate is that this amino acid is not enriched in corticocortical neurons.

The main finding of this study of ventricular fluid from over 80 subjects is that the group with either major depressive disorder or bipolar disorder had a mean 5-HIAA value that was significantly lower than neurological controls. No other difference between any of the diagnostic groups was observed for the measured compounds. This is the first study that provides evidence of selective deficit in serotonin transmission in living patients with depressive illness at a more central level than may be obtained with lumbar fluid. The conclusion was equivocal in previous studies of ventricular fluid that attempted to address this issue $e^{35}$ and results on lumbar fluid were contradictory. ${ }^{36}$ Now that it has been possible to establish an indication for a specific medication on the basis of biochemical criteria, ${ }^{4}$ it is hoped that the heterocyclic antidepressants, which have unpleasant effects, ${ }^{37}$ will be supplanted by the modern serotonin uptake blockers. ${ }^{37}$ Compounds active at serotonin $1 \mathrm{~A}$ receptors are under investigation (for example, partial agonist drugs, ${ }^{38}$ not previously considered ${ }^{4}$ ), but the clinical consequences of activation and inhibition of serotonin $1 \mathrm{~A}$ receptors need to be elucidated. $^{34}$

We gratefully acknowledge the help of Drs S L Lowe and A M Palmer, who performed some assays, and the cooperation of those involved in collection and classification of some samples, in particular Mr R D Hayward, Drs P H F Bertolucci, D M A Mann and A Poynton, and Professor L Symon. The research was supported by Astra Arcus, Brain Research Trust (Miriam Marks Department) and the Medical Research Council. N M P was supported by the Science and Engineering Research Council (SERC-CASE Award).

1 Martin JB, Beal MF, Mazurek M, Kowall MD, Growdon $\mathrm{JH}$. Some observations on the significance of neurotransmitter changes in Alzheimer's disease. In: Terry RD, transmitter changes in Alzheimer's disease. In: Terry RD, ed. Ageing

2 Davies P. Therapy for Alzheimer's disease: Choosing a target. Clin Neuropharmacol 1991;14:S24-S33.

3 Fibiger HC. Reply. Trends Neurosci 1991;14:485-6.

4 Potter WZ, Rudorfer MV, Manji H. The pharmacological treatment of depression. N Engl $f$ Med 1991;325: 633-42.

5 Moir ATB, Ashcroft GW, Crawford TBB, Eccleston D Guildberg HC. Cerebral metabolites in cerebrospinal fuid as a biochemical approach to the brain Brain 1970;93:357-68.

6 McCormick DA, Williamson A. Convergence and divergence of neurotransmitter action in human cerebral gence of neurotransmitter action in human cer

7 Procter AW, Stirling JM, Stratmann GC, Cross AJ, Bowen DM. Loss of glycine-dependent radioligand binding to DM. Loss of glycine-dependent radioligand binding to the N-methyl-D-aspartate-phencyclidine receptor com-
plex in patients with Alzheimer's disease. Neurosci Lett

8 Bartlett JR, Bridges PK, Kelly D. Contemporary indications for psychosurgery. Br f Psychiatry 1981;138:507-11.

9 Francis PT, Poynton A, Lowe SL et al. Brain amino acid concentrations and $\mathrm{Ca}^{2+}$-dependent release in intractable depression assessed antemortem. Brain Res 1989;494: 315-24.

10 Pangalos MN, Malizia AL, Francis PT, et al. Effect of psychotropic drugs on excitatory amino acid concentration in ventricular CSF from patients undergoing psycho- 
surgery for intractable depression. Brit $\mathcal{f}$ Psychiatry; 1992:160:638-42.

11 Procter AW, Palmer AM, Francis PT et al. Evidence of glutamatergic denervation and possible abnormal metabolism in Alzheimer's disease. $\mathcal{F}$ Neurochem 1988;50: 790-802.

12 Palmer AM, Sims NR, Bowen DM et al. Monoamine metabolite concentrations in lumbar cerebrospinal fluid of patients with histologically verified Alzheimer's dementia. ₹ Neurol Neurosurg Psychiatry 1984;47:481-4.

13 Francis PT, Bowen DM, Lowe SL, Neary D, Mann DM, Snowden JS. Somatostatin content and release measured in cerebral biopsies from demented patients. $\mathfrak{f}$ Neurol Sci in cerebral biopsie

14 Pangalos MN, Francis PT, Middlemiss DN, Pearson RCA, Bowen DM. Selective destruction of a sub-population of cortical neurones by suicide transport of volkensin, a lectin from Adenia volkensii. $\mathcal{f}$ Neurosci Meth 1991;40: 17-29.

15 Pangalos MN, Francis PT, Foster AC, Pearson RCA, Middlemiss DN, Bowen DM. 5-HT 1 and NMDA but not $5-\mathrm{HT}_{2}$ receptors are enriched on rat neocortical pyramidal neurones selectively destroyed by intrastriatal volkensin. $B r \mathcal{F}$ Pharmacol 1991;104:66p.

16 Carpenter MB, Sutin J. Human neuroanatomy. Baltimore: Williams and Wilkins, 1983:643-705.

17 Cheetham SC, Crompton MR, Katona CLE, Horton RW. Brain 5-HTl binding sites in depressed suicides. Psychopharmacology 1990;102:544-8.

18 Pazos A, Palacios JM. Quantitative autoradiographic mapping of serotonin receptors in the rat brain. I. Serotoninping of serotonin receptors in the rat brain.
1 receptors. Brain Res 1985;346:205-30

19 Pazos A, Probst A, Palacios JM. Serotonin receptors in the human brain-III. Autoradiographic mapping of serotonin-1 receptors. Neuroscience 1987;21:97-122.

20 Cross AJ, Slater P. High affinity serotonin binding sites in human brain: a comparison of cerebral cortex and basal ganglia. I Neural Transm 1989;76:211-9.

21 Francis PT, Pangalos MN, Bowen DM. Animal and drug modelling for Alzheimer synaptic pathology. Prog Neurobiol 1992;39:517-45.

22 Palmer AM, Hutson PH, Lowe SL, Bowen DM. Extracellular concentrations of aspartate and glutamate in rat neostriatum following chemical stimulation of frontal cortex. Exp Brain Res 1989;75:659-663.

23 Bowen DM, Najlerahim A, Procter AW, Francis PT, Murphy E. Circumscribed changes of the cerebral cortex Murphy E. Circumscribed changes of the cerebral cortex
in neuropsychiatric disorders of later life. Proc Natl Acad in neuropsychiatric disorders
Sci USA 1989;86:9504-8.

24 Procter AW, Bowen DM. Ageing, the cerebral neocortex and psychiatric disorder. In: Finch CE et al, eds. Banbury Report 27: Molecular neuropathology of ageing. Cold Spring Harbor: Cold Spring Harbor Laboratory, 1988:3-20.

25 DeFelipe J, Jones EG, Cajal on the cerebral cortex. New York: Oxford University Press, 1988:557-621.

26 Bowen DM. Treatment of Alzheimer's disease: Molecula pathology versus neurotransmitter-based therapy. Brit $f$ Psychiatry 1990;157:327-30.

27 Hardy J, Allsop D. Amyloid deposition as the central event in the aetiology of Alzheimer's disease. Trends Pharmicol Sci 1991;12:383-8.

28 Palmer AM, Stratmann GC, Procter AW, Bowen DM Possible neurotransmitter basis of behavioural changes in Plzheimer's disease. Ann Neurol 1988;23:616-20.

29 Chessell IP, Procter AW, Francis PT, Bowen DM. D-cycloserine, a putative cognitive enhancer, facilitates activation serine, a putative cognitive enhancer, facilitates activation of the NMDA receptor - ionophore

30 Halliwell JV. M-Current in human neocortical neurones Neurosci Lett 1986;67:1-6.

31 Traub M, Freedman SB. The implications of current therapeutic approaches for the cholinergic hypothesis of dementia. Dementia 1992;3:189-92.

32 Christensen IT, Reinhardt A, Nielsen B, Ebert B, Madsen U, Krogsgaard-Larsen P. Excitatory amino acid agonists and partial agonists. Drug Des Delivery 1989;5:57-71.

33 Bjork L, Cornfield LJ, Nelson DL et al. Pharmacology of the novel 5-hydroxytryptamine $1 \mathrm{~A}$ receptor antagonist (S)-5-fluoro-8-hydroxy-2-(dipropylamino)tetralin: inhibition of (R)-8-hydroxy-2-(dipropylamino)tetralininduced

34 Liau LM, Sleight AJ, Pitha J, Peroutka SJ. Characterization of a novel and potent 5-hydroxytryptamine IA receptor antagonist. Pharmacol Biochem Behav 1991;38 $555-9$

35 Curzon G, Kantamaneni BD, Van Boxel P, Gillman PK, Bartlett JR, Bridges PK. Substances related to 5-hydroxytryptamine in plasma and in lumbar and ventricular fluids of psychiatric patients. Acta Psychiat Scand 1980;61:supp 280, 3-19.

36 Gjerris A. Baseline studies on transmitter substances in cerebrospinal fluid in depression. Acta Psychiat Scand 1988;87Suppl 346.

37 Anon. If at first you do succeed. Lancet; 1991;337: 650-1.

38 Robinson DS. Antidepressant efficacy of 5-HT1A partial agonist drugs. In: Sandler $M$ et al, eds, 5-Hydroxytryptamine in psychiatry. Oxford: Oxford University Press, 1991:157-65. 